ORIGINAL ARTICLE

\title{
HIV Care continuum Outcomes: Can Ethiopia Meet the UNAIDS 90- 90-90 Targets?
}

\author{
Hailay Abrha Gesesew ${ }^{1,2 *}$, Paul Ward ${ }^{1}$, Kifle Woldemichael ${ }^{2}$, Lillian Mwanri $^{1}$
}

\section{OPEN ACCESS}

Citation: Hailay Abrha Gesesew, Paul Ward, Kifle Woldemichael, Lillian Mwanri. HIV Care continuum Outcomes: Can Ethiopia Meet the UNAIDS 90-9090 Targets?. Ethiop J Health Sci.2020;30(2): $\quad 179$. doi:http://dx.doi.org/10.4314/ejhs.v30 i2.5 Received: October 07, 2019

Accepted: November 11, 2019

Published: March 1, 2020

Copyright: (2020 Hailay Abrha Gesesew, et al. This is an open access article distributed under the terms of the Creative Commons Attribution License, which permits unrestricted use, distribution, and reproduction in any medium, provided the original author and source are credited.

Funding: Nil

Competing Interests: The authors declare that this manuscript was approved by all authors in its form and that no competing interest exists.

Affiliation and Correspondence:

${ }^{1}$ Public Health, Flinders University, Adelaide, Australia

${ }^{2}$ Epidemiology, Jimma University,

Jimma, Ethiopia

*Email: hailushepi@gmail.com

\author{
ABSTRACT
}

BACKGROUND: Ethiopia has pledged to the UNAIDS 90-90-90 framework. However, the achievements of these UNAIDS targets are not assessed in Southwest Ethiopia. Using HIV care and treatment outcomes as surrogate markers, we assessed all targets.

METHODS: Complex surrogate makers were used to assess the HIV care continuum outcomes using antiretroviral therapy data in Jimma University Teaching Hospital. Early HIV diagnosis was a surrogate marker to measure the first 90. Numbers of people on HIV treatment and who have good adherence were used to measure the second 90. To measure the third 90, we used immunological success that was measured using numbers of CD4 counts, clinical success using WHO clinical stages and treatment success using immunological and clinical successes.

RESULTS: In total, 8172 patients were enrolled for HIV care from June 2003 to March 2015. For the diagnosis target, the prevalence of early HIV diagnosis among patients on ART was 35\% $43 \%$ among children and $33.3 \%$ among adults). For the treatment target, 5299(65\%) received ART of which 1154(22\%) patients lost to follow-up or defaulted from ART treatment, and 1015(19\%) patients on treatment transferred out to other sites. In addition, $17 \%$ had fair or good adherence. Finally, $81 \%$ had immunological success, $80 \%$ had clinical success and $66 \%$ treatment success. CONCLUSIONS: The study revealed that Southwest Ethiopia achieved $35 \%, 65 \%$ and $66 \%$ of the first, second and third UNAIDS targets, a very far performance from achieving the target. These highlight further rigorous interventions to improve outcome of HIV continuum of care.

KEYWORDS: UNAIDS 90-90-90, HIV care continuum, early HIV diagnosis, discontinuation, immunologic failure, Jimma, Ethiopia

\section{INTRODUCTION}

The Joint United Nations Program on HIV and AIDS (UNAIDS) (1) and partners proposed three targets by 2020 (2). These include (i) diagnosing $90 \%$ of the total number of people living with HIV (first 90), (ii) delivering antiretroviral therapy (ART) to $90 \%$ of those diagnosed or $81 \%$ of total number HIV positive people (second 90 ), and attaining viral suppression for $90 \%$ of patients getting treatment or $73 \%$ of the total number HIV positive people (third 90 ). 
The effectiveness of ART program of a country relies on the series of steps a person with HIV takes from diagnosis to successful HIV treatment, and this cascade is named as HIV care continuum (HCC)(3). HCC comprises HIV testing and diagnosis, screening for eligibility of ART, lifelong retention in the care, and clinical and immunologic successes and virological suppression through ART compliance adherence. Several factors affect the success of each step of the cascade, and this in turn, will make the success of the ambitious 90-90-90 targets challenging $(3,4)$.

Since the inception of the targets in 2014, few estimates have been reported about the progress, and no country has achieved these targets except Sweden. For the HIV diagnosis target, Sweden was reported to have achieved $90 \%$ whereas Yemen has achieved only $11 \%$ (2). For the treatment target, Sweden attained $97.1 \%$ followed by Switzerland (71\%) whereas Yemen and Afghanistan attained 3\% each respectively (2). Sweden, Switzerland, Australia, USA and Russia recorded 95\%, 68\%, 62\%, 30\% and $9 \%$ virological suppression respectively (2). Botswana found overall coverage levels that nearly achieved the UNAIDS target(5).

Ethiopia is a low-income country with an HIV prevalence of $0.9 \%$ in 2016 (6). ART program was initially started in 2003 in 12 hospitals where patients pay for the treatment (7), but the program was provided for free in 22 hospitals since 2005 with aid from the Global Fund, World Bank, and PEPFAR (8). As a result, 535,069 people with HIV 'ever started' ART in more than 1000 health centers and hospitals in 2015(9). Ethiopia, like other countries in SSA, has subscribed to the UNAIDS 90-90-90 targets (10). However, no assessment was conducted about the progress. The current study investigated HIV care cascade outcomes as surrogates for the 90-90-90 targets using 12 years' retrospective data from Jimma University Teaching Hospital, Southwest Ethiopia.

\section{METHODS}

Study design, study setting and study participants: A retrospective cohort study was undertaken in Jimma University Teaching Hospital (JUTH) ART clinic, Jimma, Southwest Ethiopia. The data covered from 21 June 2003 to 15 March 2015. Jimma Town is the capital city of Jimma Zone in Oromia Region, and this region had the highest number of HIV cases in the country. Jimma is also located near Gambella Region which had the highest HIV prevalence rate $(6.5 \%)$ in Ethiopia (11). Furthermore, near Jimma Town, there is a refugee camp with a number of refugees from different African countries; this increases the risk of HIV in the area, as observed in other areas (12).

JUTH provides several HIV services including voluntary counseling and testing (VCT), prevention of mother to child transmission (PMTCT), providerinitiated HIV testing and counseling (PITC), ART and treatment for opportunistic infections (OIs) since 2003. From 2015 to mid 2016, according to the national (13) and WHO (14) guidelines, HIV infected people are eligible to ART if their CD4 counts is below 500 cells $/ \mu$ irrespective of WHO clinical stage or WHO clinical stage is 3 or 4 irrespective of CD4 counts. All Tuberculosis patients, children, pregnant and breast-feeding mothers are eligible for ART in spite of CD4 count or WHO clinical stage. However, since the end of 2016, Ethiopia has started 'test and treat' strategy where every HIV positive person starts the treatment although this is yet to be rolled out all over the country (15).

Table 1: Ideal measure and surrogate markers for UNAIDS 90-90-90 targets, 2016.

\begin{tabular}{lll}
\hline UNAIDS Target* & Ideal measure & Surrogate measures \\
\hline 1 & $\begin{array}{l}\text { Number of HIV infected } \\
\text { individuals aware of their }\end{array}$ & Number of patients with delayed HIV diagnosis \\
& $\begin{array}{l}\text { HIV status } \\
\text { Number of HIV infected } \\
\text { population receiving ART }\end{array}$ & $\begin{array}{l}\text { Number of HIV infected population on ART, number of } \\
\text { discontinued, number of patients with fair/poor adherence }\end{array}$ \\
3 & $\begin{array}{l}\text { Number of patients with } \\
\text { undetected viral count } \\
\text { copies/mL) }\end{array}$ & success of patients with immunological, clinical and treatment \\
\hline
\end{tabular}

*Target 1 (HIV diagnosis): 90\% of patients knowing their status; Target 2 (HIV treatment): 90\% of diagnosed patients receiving treatment; Target 3 (virological suppression): $90 \%$ of patients on antiretroviral therapy (ART) achieving viral suppression

DOI: http://dx.doi.org/10.4314/ejhs.v30i2.5 
Measurements: Table 1 presents the complex surrogate makers/indicators which were used to assess the HIV care continuum outcomes and further show an overall proxy surrogate for UNAIDS targets. To measure the diagnosis target, delayed HIV diagnosis (DHD) was considered as a surrogate marker. DHD reflects that people are suspicious of their HIV status before diagnosis but late for knowing their HIV status(16). To measure the treatment target, the number of people on ART out of those diagnosed was used as a surrogate marker. In addition, to assess whether the treatment intake was sustainable or not, number of people who were lost to follow-up or had defaulted (had discontinued) or transferred out, and number of people who had fair or poor ART compliance were considered. For measuring the viral suppression target, we used number of $\mathrm{CD} 4$ counts to assess immunological success and WHO clinical stages to assess clinical success. Treatment success, measured by the rate of immunological and clinical successes, was used as a final surrogate measure to increase the probability of estimating viral suppression. The measurement for ART discontinuation was published elsewhere (17). The operational definitions for delayed HIV diagnosis (late presentation for HIV care), ART adherence, and immunological, clinical and treatment successes are published elsewhere(18).

Data source and procedures: The data in ART clinic in JUTH is stored in a database center called the comprehensive care center patient application database (C-PAD). The C-PAD is an electronic medical records (EMR) system and uses the Structured Query Language (SQL) format. The database was designed in 2007 and has been functional since then. The data entry process is undertaken by two data clerks and this ensures data completeness, accuracy and reliability. In addition, the International Center for AIDS Care and Support (ICAP) at Colombia University delivered technical assistance on the data management system. We excluded records with no baseline CD4 count and WHO clinical stage, and ART start date during the analysis of DHD. Similarly, for the analysis of immunological and clinical successes, we excluded records with no record of CD4 count and WHO clinical stage at baseline and after six months.

Data analyses: Data were edited, explored and cleaned before analysis. Descriptive statistics was performed to describe study population characteristics and produce summary statistics. We used proportions and percentages for categorical data, and for continuous data, we used mean, median, range and line graphs. Eleven years trends for $\mathrm{DHD}$, discontinuation and immunologic failure for patients on ART were described by line graphs. We excluded data for years 2003 and 2015 while producing line graph as the number of months in both years are incomplete. For each graph, we developed a best-fit equation for the trend line, and shown in the graph if $\mathrm{R}^{2}$ is above $75 \%$. Estimated survival time for children and adults was calculated using Kaplan-Meier. We performed the data analysis using Statistical Package for the Social Sciences (SPSS) 22.0.

Ethical statement: The study was approved by Social and Behavioral Research Ethics Committee (SBREC) at Flinders University (Project number: 7086) and Institutional Review Board (IRB) of College of Health Sciences at Jimma University (Ref No: RPGC/386/2016). The data access permission was obtained from JUTH board. We did not involve any participant in this study, we only extracted anonymised data from the database.

\section{RESULTS}

Characteristics of cohort: From the available ART data, 5,299 out of 8,172 available patients (64.8\%) were on ART, and the remaining included: eligible and ready for ART $(0.1 \%)$, eligible for ART $(0.2 \%)$ and on pre-ART $(34.9 \%)$. There were $399(7.5 \%)$ children and $4900(92.5 \%)$ adults registered for ART. Table 2 depicts the characteristics (clinical and non-clinical) of the study participants.

Southwest Ethiopia cascade of the UNAIDS 9090-90 targets: Figure 1 presents the Ethiopian cascade of the UNAIDS 90-90-90 Targets, and are reported in detail as follows. 
Table 2: Clinical and non-clinical characteristics of HIV infected people enrolled in ART care in Southwest Ethiopia from 2003 to 2015.

\begin{tabular}{|c|c|c|c|}
\hline \multicolumn{2}{|r|}{ Variable } & \multirow{2}{*}{$\begin{array}{l}\text { Children }(\mathrm{N}=399), \mathbf{N}(\%) \\
21(5.3)\end{array}$} & \multirow{2}{*}{ Adult $(\mathrm{N}=4900), \mathrm{N}(\%)$} \\
\hline Age in years & $<1$ & & \\
\hline & $1-<5$ & $146(36.6)$ & ---------- \\
\hline & $5-<15$ & $232(58.1)$ & ---------- \\
\hline & $15-<25$ & --------- & $711(14.5)$ \\
\hline & $25-<50$ & ---------- & $3937(80.3)$ \\
\hline & $50+$ & ---------- & $252(5.2)$ \\
\hline & Median (range) & $6(<1-14)$ & $30(15-81)$ \\
\hline \multicolumn{2}{|c|}{ ART follow up time in months, median (range) } & $40(0-116)$ & $49(0-137)$ \\
\hline \multicolumn{2}{|c|}{ Estimated survival time, months, median $(95 \% \mathrm{CI})$} & $104.2(99.8-108.5)$ & $121.9(120.3-123.5)$ \\
\hline \multirow[t]{2}{*}{ Sex } & Male & $209(52.4)$ & $1971(40.2)$ \\
\hline & Female & $190(47.6)$ & $2929(59.8)$ \\
\hline \multirow[t]{3}{*}{ Marital status ${ }^{b}$} & Never married & --------- & $897(20.9)$ \\
\hline & Married & ---------- & 2094(48.7) \\
\hline & Separated/divorced/widowed & ---------- & $1311(30.5)$ \\
\hline \multirow[t]{3}{*}{ Education $^{b}$} & No education & ---------- & $945(21.9)$ \\
\hline & Primary & ---------- & $1687(39.1)$ \\
\hline & Secondary and above & ---------- & $1685(39)$ \\
\hline \multirow[t]{2}{*}{ Religion $^{b}$} & Muslim & $47(26.1)$ & $1402(32.6)$ \\
\hline & Christian $^{\mathrm{a}}$ & $133(73.9)$ & 2893(67.4) \\
\hline \multirow{5}{*}{$\begin{array}{l}\text { Baseline } \\
\text { classification }^{b} \\
\text { Baseline CD4 count } \\
\text { category }^{b}\end{array}$} & 1 or 2 & $108(49.5)$ & $1355(45.7)$ \\
\hline & 3 or 4 & $110(50.5)$ & $1608(54.3)$ \\
\hline & No immunosuppression & $72(20.6)$ & ---------- \\
\hline & $\begin{array}{l}\text { Moderate/severe } \\
\text { immunosuppression }\end{array}$ & $277(79.4)$ & ---------- \\
\hline & Median (range) CD4 count & $282(0-2250)$ & ---------- \\
\hline \multirow{3}{*}{$\begin{array}{l}\text { Baseline CD4 count } \\
(\text { cells } / \mathrm{mm} 3)^{\mathrm{b}}\end{array}$} & $<200$ & --------- & $3275(73.6)$ \\
\hline & $\geq 200$ & ---------- & $1174(26.4)$ \\
\hline & Median (range) & & $156(0-1313)$ \\
\hline \multirow{4}{*}{$\begin{array}{l}\text { History of Tb/HIV } \\
\text { co-infection }^{\mathrm{b}} \\
\text { ARV adherence }\end{array}$} & No & $285(71.4)$ & $3533(72.1)$ \\
\hline & Yes & $114(28.6)$ & $1367(27.9)$ \\
\hline & Good & $319(79.9)$ & $4064(82.9)$ \\
\hline & Fair or poor & $80(20.1)$ & $836(17.1)$ \\
\hline \multirow{4}{*}{$\begin{array}{l}\text { Cotrimoxazole } \\
\text { adherence }^{b} \\
\text { Hx of HIV testing }\end{array}$} & Good & $315(78.9)$ & $4119(94.4)$ \\
\hline & Fair or poor & $84(21.1)$ & $762(15.6)$ \\
\hline & Yes & $399(100)$ & $2860(58.4)$ \\
\hline & No & $0(0)$ & $2040(41.6)$ \\
\hline \multirow[t]{2}{*}{ ART shift ${ }^{b}$} & No & $214(97.7)$ & $3190(99.1)$ \\
\hline & Yes & $5(2.3)$ & $29(0.9)$ \\
\hline \multirow{2}{*}{$\begin{array}{l}\text { Baseline functional } \\
\text { status }^{b}\end{array}$} & Appropriate & $170(42.6)$ & --------- \\
\hline & Delay or regression & $229(57.4)$ & ---------- \\
\hline \multirow{2}{*}{$\begin{array}{l}\text { Baseline functional } \\
\text { status }^{b}\end{array}$} & Work or Ambulatory & ---------- & $3064(68.1)$ \\
\hline & Bedridden & ---------- & 1437(31.9) \\
\hline \multirow{2}{*}{$\begin{array}{l}\text { Timing to HIV } \\
\text { diagnosis }\end{array}$} & Early & $162(43)$ & $894(33.3)$ \\
\hline & Late & $215(57)$ & $1788(66.7)$ \\
\hline \multirow[t]{2}{*}{ Clinical failure $^{\mathrm{b}}$} & No & $165(77.1)$ & $2261(80.5)$ \\
\hline & Yes & $49(22.9)$ & $546(19.5)$ \\
\hline \multirow[t]{3}{*}{ Immunologic failure ${ }^{b}$} & No & $295(84.8)$ & $3164(80.3)$ \\
\hline & Yes & $53(15.2)$ & $775(19.7)$ \\
\hline & No & $126(67.4)$ & $1493(65.7)$ \\
\hline Treatment failure $^{b}$ & Yes & $61(32.6)$ & $780(34.3)$ \\
\hline
\end{tabular}

${ }^{\mathrm{a}}$ Orthodox, Catholic, Protestant; ${ }^{\mathrm{b}}$ only valid percentage is calculated; ARV=antiretroviral therapy 


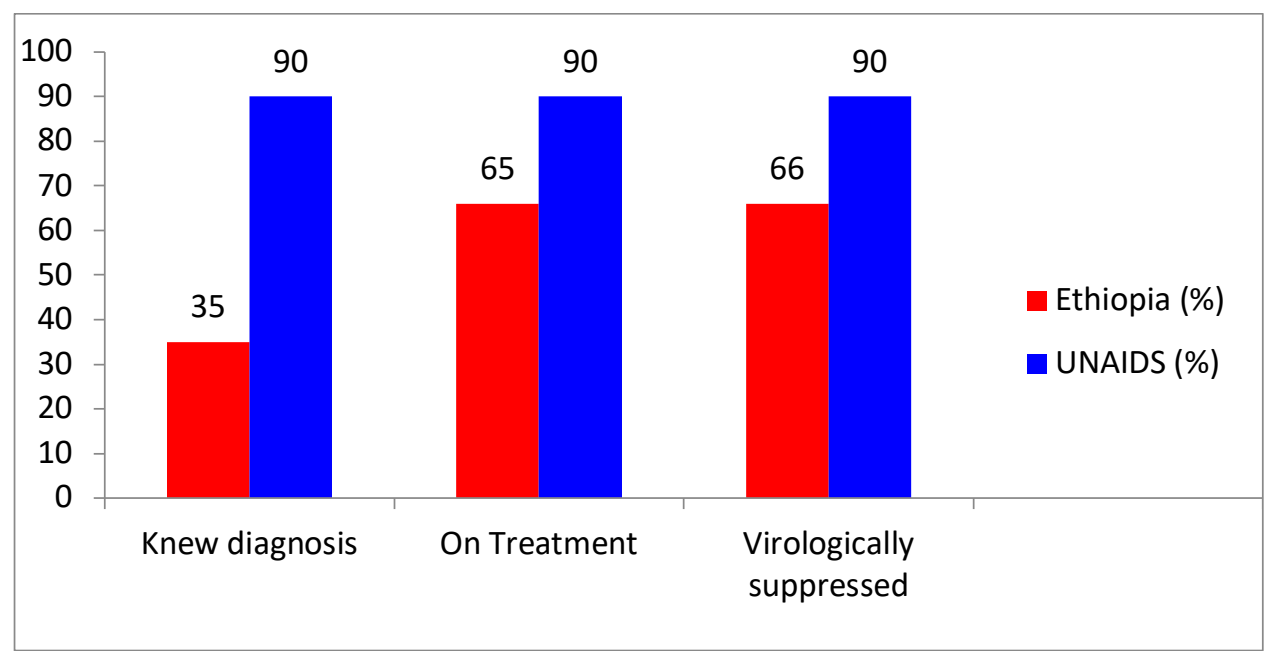

Figure 1: Southwest Ethiopia cascade of the UNAIDS 90-90-90 Targets, 2016

UNAIDS target 1-diagnosis target: Overall, $65.5 \%$ of the patients were deemed DHD in which females accounted for $64.3 \%$. This indicates that only $34.5 \%$ of the patients knew their status timely (females contributed for $35.7 \%$ ). When it was analyzed by age, the prevalence of DHD was $57 \%$ among children and $66.7 \%$ among adults. The analysis of DHD showed slightly upward trends (Figure 2).

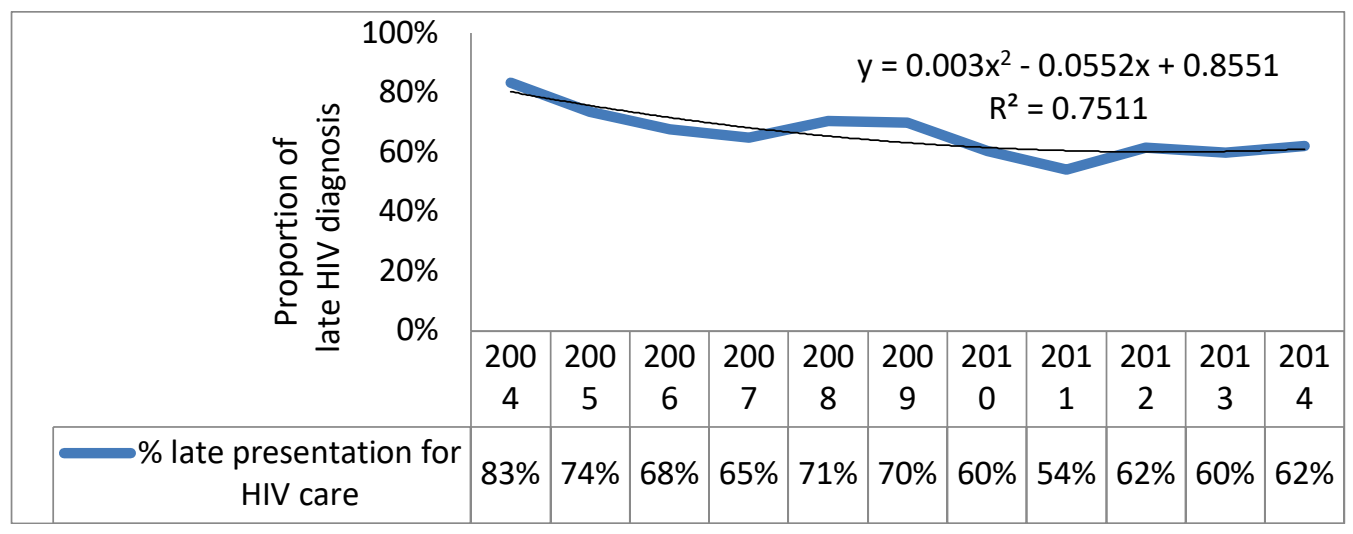

Figure 2: Trends in the percentage distribution of late presentation for HIV care among HIV infected people on ART, Southwest Ethiopia, 2004-2014

$N B$. The thin black in the graph shows the predicted equation for the trend of late presentation for HIV care displayed in the graph using thick blue line.

UNAIDS target-ART treatment target: Out of the 8,172 individuals who were diagnosed with HIV infection and enrolled for HIV care, 5,299 $(65 \%)$ patients received ART. Of those enrolled in ART, $1154(21.9 \%)$ patients discontinued the treatment (females accounted for 54.8\%). Additionally, 1015(19.3\%) patients transferred out
(TO) to other sites, and of these, females accounted for $54.6 \%$. A total of $228(4 \%)$ and $688(13 \%)$ patients had fair and poor adherence respectively. The significant rate of ART discontinuation, TO and ART non-adherence indicates that the treatment was not provided sustainably. Discontinuation from ART has been a big 
challenge and its trend in the recent years was rising (Figure 3). Table 3 demonstrates yearly number of patients enrolled in HIV care and treatment and their outcomes.

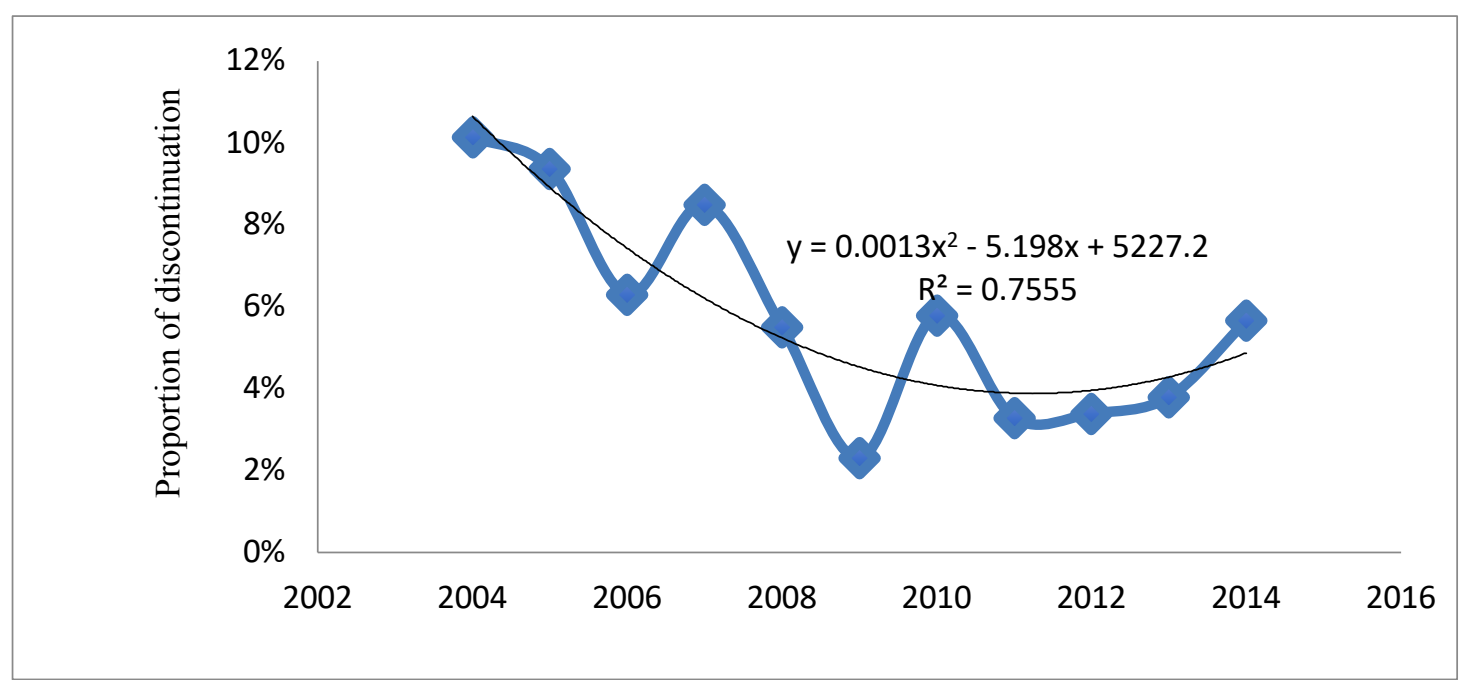

Figure 3: Trends in the percentage distribution of discontinuation from ART among HIV infected people on ART, Southwest Ethiopia, 2004-2014

$N B$. The thin black in the graph shows the predicted equation for the trend of discontinuation from ART displayed in the graph using thick blue line.

UNAIDS target 3-Viral suppression target: In total, $80.7 \%$ had immunological success, $80.3 \%$ had clinical success and $65.8 \%$ of patients had treatment success. This depicts that at least an estimated $66 \%$ of patients achieved viral suppression. The trend of immunologic failure has been increasing in the recent years (Table 3), indicating that the trend of immunologic success is deteriorating.

Table 3. Annual number of patients enrolled in ART care and their outcomes

\begin{tabular}{|c|c|c|c|c|c|c|c|c|}
\hline \multirow[b]{2}{*}{ Year } & \multirow{2}{*}{$\begin{array}{c}\text { New } \\
\text { enrollment } \\
\text { (a) }\end{array}$} & \multicolumn{5}{|c|}{ Outcome final, n (\%) } & \multicolumn{2}{|c|}{ Immunologic status, n (\%) } \\
\hline & & Dead (b) & $\begin{array}{l}\text { Discontinuation } \\
\text { (c) }\end{array}$ & $\begin{array}{l}\text { Transfer } \\
\text { out(d) }\end{array}$ & $\begin{array}{l}\text { Alive and on } \\
\text { ART (e) }\end{array}$ & $\begin{array}{l}\text { Total in } \\
\text { Cohort } \\
\text { (f) }\end{array}$ & Success & Failure \\
\hline $2003^{\mathrm{a}}$ & 8 & $0(0)$ & $1(12.5)$ & $0(0)$ & $7(87.5)$ & 8 & $5(100)$ & $0(0)$ \\
\hline 2004 & 62 & $1(1.4)$ & $7(10.1)$ & $1(1.4)$ & $60(87.0)$ & 69 & $17(68)$ & $8(32)$ \\
\hline 2005 & 484 & $28(5.1)$ & $51(9.4)$ & $9(1.7)$ & $456(83.8)$ & 544 & $301(78.2)$ & $84(21.8)$ \\
\hline 2006 & 973 & $66(4.6)$ & $90(6.3)$ & $71(5.0)$ & $1202(84.1)$ & 1429 & $911(77.3)$ & $267(22.7)$ \\
\hline 2007 & 622 & $53(2.9)$ & $155(8.5)$ & $137(7.5)$ & $1479(81.1)$ & 1824 & $1333(78.8)$ & $358(21.2)$ \\
\hline 2008 & 555 & $45(2.2)$ & $112(5.5)$ & $97(4.8)$ & $1780(87.5)$ & 2034 & $1698(79.4)$ & $441(20.6)$ \\
\hline 2009 & 566 & $42(1.8)$ & $54(2.3)$ & $109(4.6)$ & $2141(91.3)$ & 2346 & $2077(79.3)$ & $543(20.7)$ \\
\hline 2010 & 481 & $23(0.9)$ & $152(5.8)$ & $81(3.1)$ & $2366(90.2)$ & 2622 & $2429(79.9)$ & $610(20.1)$ \\
\hline 2011 & 461 & $29(1.0)$ & $93(3.3)$ & $112(4.0)$ & $2593(91.7)$ & 2827 & $2778(80.8)$ & $659(19.2)$ \\
\hline 2012 & 383 & $11(0.4)$ & $101(3.4)$ & $103(3.5)$ & $2761(92.8)$ & 2976 & $3048(81)$ & $714(19)$ \\
\hline 2013 & 324 & $17(0.6)$ & $117(3.8)$ & $107(3.5)$ & $2844(92.2)$ & 3085 & $3247(80.8)$ & $770(19.2)$ \\
\hline 2014 & 320 & $9(0.3)$ & $179(5.7)$ & $158(5.0)$ & $2818(89.1)$ & 3164 & $3428(80.7)$ & $822(19.3)$ \\
\hline $2015^{\mathrm{a}}$ & 60 & $2(0.1)$ & $42(1.5)$ & $30(1.0)$ & $2763(97.4)$ & 2878 & $3459(80.7)$ & $828(19.3)$ \\
\hline Overall & & $326(6.2)$ & $1154(21.9)$ & $1015(19.3)$ & $2763(52.5)$ & 5299 & $3459(80.7)$ & $828(19.3)$ \\
\hline
\end{tabular}

${ }^{a}$ Data for years 2003 and 2015 were not from complete number of months and were excluded from trend graph. $\mathrm{e}=\mathrm{f}-\mathrm{b}-\mathrm{c}-\mathrm{d}$; where $\mathrm{f}=\mathrm{e}$ (previous year) $+\mathrm{a}$ (current year) 


\section{DISCUSSION}

This study was conducted to assess HIV care continuum outcomes in each cascade and provide important insights about the progress of the UNAIDS 90-90-90 targets in Ethiopia. There were high prevalence rates of DHD, ART discontinuation, non-adherence, and immunological, clinical and treatment failures.

High prevalence rate of DHD implies that a number of people did not know their HIV status. In the current study, only $35 \%$ of patients knew their status timely, a very low performance compared with the UNAIDS target and the $45 \%$ performance by SSA(19) . Additionally, about 40\% (3225/8172) of participants did not have a history of HIV testing before diagnosis in the current study. As reflected in the findings, only $65 \%$ of people diagnosed with HIV infection were receiving ART. Even among those who were receiving ART, $22 \%$ of them had discontinued the treatment, $19 \%$ had been transferred out to other ART sites, and $17 \%$ had fair or poor ART adherence. These indicate that a considerable number of patients were not receiving ART sustainably. This is lesser than the target set by UNAIDS, and the findings from SSA (19) reporting $86 \%$ achievement.

Given that the access for Plasma HIV-1 RNA (viral load) monitoring is very limited and is not available for routine services in Ethiopia, treatment successes was used as a surrogate marker for the virological suppression. Accordingly, $66 \%$ of patients on ART showed treatment success reflecting achieved viral suppression. This performance is also lower than the UNAIDS target, and the $76 \%$ achievement by SSA (19). Evidence shows(20) have shown that number of CD4 count determines virological failure or suppression unlike some others that reported the reverse(21).

In the current study, compared to males, females had high proportion of DHD, discontinuation from ART, and immunological, clinical and treatment failures. This could be attributed to a variety of reasons including: (i) high levels of stigma in females which may deter them from HIV care seeking (22), and (ii) given that females are living in a male dominated society in Ethiopia, they face barriers (23) to accessing HIV care, and (iii) the implementation of integrated modern and traditional medicine in Ethiopia is limited, and patients could not attend the care timely and sustainably (24).

To reduce DHD, the use of technology is one of the recommended strategies. Amukele and colleagues' study showed that Malawi is piloting drones for transporting laboratory specimens to improve early HIV diagnosis in infant with the aid of UNICEF(25). Furthermore, community-based HIV testing (26), mobile text messages (27) and home-based HIV testing (28) are also other recommended programs to meet the first UNAIDS target via overcoming DHD. In addition, inspiring repeat HIV testing(29), 'opt out' testing (30) and self-HIV testing(31) can close the gap in DHD in Ethiopia and other low-income countries.

To improve uptake of ART, effective linking strategies to care, revising eligibility criteria for ART and retaining patients in care help to step up from diagnosis to successful treatment(32). For example, immediate or same day ART initiation after diagnosis was found to be an effective linking strategy in resource-limited settings (33). Community distribution of ART is also another effective innovation for ART delivery as demonstrated by studies elsewhere (27). For countries with civil unrest or other humanitarian disasters, Médicins Sans Frontières (MSF) introduced a new approach called "runaway packs" that enables individuals to pick up their medications to be used for a long duration (34).

To improve the goal of virological suppression, strategies that heighten treatment effectiveness such as adherence clubs (2), treatment simplification to single dose combinations (35) and access to viral load testing (27) should be considered. Peter and colleagues(36) strongly suggested the need for scaling up of viral load testing should HIV treatment and virological suppression goals be attained. Ethiopia should also learn about the rollout of GenXpert instruments for HIV viral load and the use of drones for early infant diagnosis from Kenya, Malawi and Zimbabwe (27).

Overall, the 90-90-90 UNAIDS targets is an ambitious initiative and the current performance-35-65-66 - seems too high to meet 
the coverage target for Ethiopia. This underscores the need for concreted efforts to implement the aforementioned innovative strategies and effective programs. In addition, it also depends on the commitment of funding organizations and political stakeholders (37). The lack of sufficient funds and human resources to deliver ART for HIV infected people, together with the raising ART drug resistance, will make the success of the goal to halt AIDS by 2030 very difficult(38). However, Ethiopia would use Health Extension Workers as potential human resources for the success of 90-9090 targets. Additionally, to curb the scarcity of human resources for health, Ethiopia is addressing this through decentralization, task shifting and deployment of Health Development Army. The impact of community-based treatment for improving HIV care retention, ART adherence and viral suppression has been supported by previous studies(39).

This retrospective study has several limitations. The real number of individuals infected with HIV or persons who have been diagnosed with HIV cannot be obtained or estimated from a routinely collected programmatic data. Immunologic, clinical and treatment successes might not show the actual viral suppression as stated by Rutherford and colleagues(40). However, this could be a valid surrogate for resourceconstrained HIV burden countries where Plasma HIV-1 RNA is not routinely performed. JUTH is found in Oromia Region where the overall regional HIV prevalence was $1 \%$, and the findings from this setting may not represent other regional states with high HIV prevalence such as Gambella (6.5\%) (11). Measuring the success rate of UNAIDS 9090-90 targets has its own limitations. Comparisons over time and space may be misleading because of the introduction of variety of HIV programs such as "treat all", testing and linkage and seek-testtreat-succeed model (40). HIV infected patients coming for care at lower viral counts were much less likely to commence ART than patients presenting at higher viral counts despite that all are eligible, and this will lead to selection bias (41).

In conclusion, of the goal $90-90-90$ set by the UNAIDS, Ethiopia achieved an estimated percentage of 35-65-66. Of a particular concern is that DHD and discontinuation from ART are found high for females compared to males. In addition, immunological, clinical and treatment failures rates are higher for females that seek special attention in each series of HIV care continuum. Because the current system/infrastructure has not been able to support the attainment of UNAIDS targets, we recommend strengthening or establishing the following programs to hit the targets: implementing additional and rigorous innovative methods, testand-treat strategy, community-based ART distribution, strategies during conflict zones including runaway packs, and GenXpert for HIV viral load testing in areas where there is shortage of RNA viral load testing.

\section{ACKNOWLEDGEMENTS}

We acknowledge JUTH for providing access to the data. Since this study was employed as part of a $\mathrm{PhD}$ program, the Australian Government Research Training (RTP) Program Scholarship (at Flinders University) supported the PhD program. RTP had no role in designing the study, collecting and analyzing the data, deciding to publish its findings, or preparing the manuscript. No specific grant was received for this research.

\section{ABBREVIATIONS}

ART: antiretroviral therapy; DHD: delayed HIV diagnosis; JUTH: Jimma University Teaching Hospital; HCT: HIV counseling and testing; HIV: Human IImmunodeficiency virus; PITC: provider-initiated HIV testing and counseling; PMTCT: prevention of mother to child transmission; SSA: Sub-Saharan Africa; UNAIDS: The Joint United Nations Program on HIV and AIDS; WHO: World Health Organization

\section{REFERENCES}

1. UNAIDS. The Joint United Nations Program on HIV and AIDS Geneva, Switzerland2016 [cited 20169 October]. Available from: http://www.unaids.org/en/aboutunaids.

2. Levi J, Raymond A, Pozniak A, Vernazza P, Kohler P, Hill A. Can the UNAIDS 90-90-90 target be achieved? A systematic analysis of national HIV treatment cascades. BMJ Global Health. 2016;1(2):e000010.

3. Kranzer K, Govindasamy D, Ford N, Johnston V, Lawn SD. Quantifying and addressing losses along the continuum of care for people living with HIV infection in sub-Saharan Africa: a systematic

DOI: http://dx.doi.org/10.4314/ejhs.v30i2.5 
review. Journal of the International AIDS Society. 2012;15(2):17383.

4. Hull MW, Wu Z, Montaner JS. Optimizing the engagement of care cascade: a critical step to maximize the impact of HIV treatment as prevention. Curr Opin HIV AIDS. 2012;7(6):57986.

5. Gaolathe T, Wirth KE, Holme MP, Makhema J, Moyo S, Chakalisa U, et al. Botswana's progress toward achieving the 2020 UNAIDS 90-90-90 antiretroviral therapy and virological suppression goals: a population-based survey. Lancet HIV. 2016;3(5):e221-30.

6. CSA, ICF. Ethiopia Demographic and Health Survey 2016: HIV Report. Addis Ababa, Ethiopia, and Rockville, Maryland, USA: Central Statistical Agency (CSA) [Ethiopia] and ICF; 2018.

7. Mekonnen Yared, Rachel Sanders, Senait Tibebu, Emmart P. Equity and Access to ART in Ethiopia. USA: USAID, Initiative HP; 2010 2010. Report No.: 1.

8. Mitiku H, Abdosh T, Teklemariam Z. Factors affecting adherence to antiretroviral treatment in harari national regional state, eastern ethiopia. Isrn aids. 2013;2013:960954.

9. Assefa Y, Gilks CF, Lynen L, Williams O, Hill PS, Tolera $\mathrm{T}$, et al. Performance of the Antiretroviral Treatment Program in Ethiopia, 2005-2015: strengths and weaknesses toward ending AIDS. Int J Infect Dis. 2017;60:70-6.

10. UNAIDS. UNAIDS joins forces with the one million community health workers campaign to achieve the 90-90-90 treatment target Geneva, Switzerland2016 [cited 20169 October]. Available from:

http://www.unaids.org/en/resources/presscentre/feat urestories/2016/february/20160202_909090.

11. CSA, ICF. Ethiopian Demographic Health Survey 2011. Addis Ababa and Calverton: Central Statistical Agency (Ethiopia) and ICF International; 2012.

12. Rowley EA, Spiegel PB, Tunze Z, Mbaruku G, Schilperoord M, Njogu P. Differences in HIVrelated behaviors at Lugufu refugee camp and surrounding host villages, Tanzania. Conflict and Health. 2008;2(1):13.

13. MoH. National Guidelines for Comprehensive HIV Prevention, Care and Treatment: Federal Democrtic Republic of Ethiopia, MoH. Addis Ababa: Minstry of Health; 2014.

14. WHO. Antiretroviral therapy for HIV infection in adults and adolescents. Geneva: WHO; 2010.
15. WHO. Consolidated guidelines on the use of antiretroviral drugs for treating and preventing HIV infection - Recommendations for a public health approach - Second edition. . Geneva: World health Organization; 2016.

16. Howells J. Delayed HIV testing in HIV-positive sub-Saharan Africans [PhD]: Royal Holloway, University of London; 2014.

17. Gesesew HA, Lillian M, Paul W, Kifle W H, Garuma T F. Factors associated with discontinuation of anti-retroviral therapy among adults living with HIV/AIDS in Ethiopia: a systematic review protocol. JBI Database of Systematic Reviews \& Implementation Reports. 2016;14(2):27-36.

18. Gesesew HA, Ward P, Woldemichael K, Mwanri L. Immunological failure in HIV-infected adults from 2003 to 2015 in Southwest Ethiopia: a retrospective cohort study. BMJ Open. 2018;8(8):e017413.

19. UNAIDS. The gap report. Geneva, Switzerland; 2014.

20. Wolff M, Shepherd BE, Cortes C, Rebeiro P, Cesar $\mathrm{C}$, Wagner Cardoso S, et al. Clinical and Virologic Outcomes After Changes in First Antiretroviral Regimen at 7 Sites in the Caribbean, Central and South America Network. Journal of acquired immune deficiency syndromes (1999). 2016;71(1):102-10.

21. Rutherford GW, Anglemyer A, Easterbrook PJ, Horvath T, Vitoria $M$, Penazzato $M$, et al. Predicting treatment failure in adults and children on antiretroviral therapy: a systematic review of the performance characteristics of the 2010 WHO immunologic and clinical criteria for virologic failure. AIDS (London, England). 2014;28 Suppl 2:S161-9.

22. Paudel V, Baral KP. Women living with HIV/AIDS (WLHA), battling stigma, discrimination and denial and the role of support groups as a coping strategy: a review of literature. Reproductive Health. 2015;12:53.

23. Aziz M, Smith KY. Challenges and Successes in Linking HIV-Infected Women to Care in the United States. Clinical Infectious Diseases. 2011;52(suppl 2):S231-S7.

24. Kebede DK, Alemayehu A, Binyam G, Yunis M. A historical overview of traditional medicine practices and policy in Ethiopia. EthiopJHealth Dev. 2006;20(2):127-34.

25. Amukele TK, Sokoll LJ, Pepper D, Howard DP, Street J. Can Unmanned Aerial Systems (Drones) Be Used for the Routine Transport of Chemistry, 
Hematology, and Coagulation Laboratory Specimens? PloS one. 2015;10(7):e0134020.

26. Chamie G, Clark TD, Kabami J, Kadede K, Ssemmondo E, Steinfeld R, et al. A hybrid mobile approach for population-wide HIV testing in rural east Africa: an observational study. Lancet Hiv. 2016;3(3):E111-E9.

27. UNAIDS. 90-90-90: On the right track towards the global target. 2016.

28. Kwame S, Chaila JM, Sian F, Ab S, Sam G, Richard H, et al. Uptake of HIV Testing in the HPTN 071 (PopART) Trial in Zambia. Conference on Retroviruses and Opportunistic Infections; Boston, USA2016.

29. Mayer K, Gazzard B, Zuniga JM, Amico KR, Anderson J, Azad Y, et al. Controlling the HIV epidemic with antiretrovirals: IAPAC consensus statement on treatment as prevention and preexposure prophylaxis. Journal of the International Association of Providers of AIDS Care. 2013;12(3):208-16.

30. Melaku Z, Lamb MR, Wang C, Lulseged S, Gadisa $\mathrm{T}$, Ahmed S, et al. Characteristics and outcomes of adult Ethiopian patients enrolled in HIV care and treatment: a multi-clinic observational study. $B M C$ public health. 2015;15.

31. Napierala Mavedzenge S, Baggaley R, Corbett EL. A review of self-testing for HIV: research and policy priorities in a new era of HIV prevention. Clinical infectious diseases : an official publication of the Infectious Diseases Society of America. 2013;57(1):126-38.

32. Medley A, Bachanas P, Grillo M, Hasen N, Amanyeiwe U. Integrating prevention interventions for people living with HIV into care and treatment programs: a systematic review of the evidence. Journal of acquired immune deficiency syndromes (1999). 2015;68 Suppl 3:S286-96.

33. Sydney R, Mhairi M, Matthew PF, Cynthia N, Constance $\mathrm{M}$, Given $\mathrm{M}$, et al. Viral reservoirs/antiretroviral therapy randomized clinical trials, initiating ART at a patient's first clinic visit: the RapIT randomized trial. Conference on Retroviruses and Oppurtunistic Infection (CROI) 2016; Boston, Massachusetts2016.
34. Cecilia FA, Vicente DJ, Elena G, Augusto L, Johana V. Implementing a test and treat programme in a rural conflict-affected area of South Sudan. MSF Sceintific day 2016; Yambio, South Sudan2016.

35. Vitoria $M$, Ford N, Doherty $M$, Flexner C. Simplification of antiretroviral therapy: a necessary step in the public health response to HIV/AIDS in resource-limited settings. Antivir Ther. 2014;19 Suppl 3:31-7.

36. Peter $\mathrm{T}$, Ellenberger D, Kim AA, Boeras D, Messele T, Roberts $\mathrm{T}$, et al. Early antiretroviral therapy initiation: access and equity of viral load testing for HIV treatment monitoring. The Lancet Infectious diseases. 2016.

37. Sidibe M, Loures L, Samb B. The UNAIDS 90-9090 target: a clear choice for ending AIDS and for sustainable health and development. Journal of the International AIDS Society. 2016;19(1):21133.

38. Wang H, Wolock TM, Carter A, Nguyen G, Kyu $\mathrm{HH}$, Gakidou E, et al. Estimates of global, regional, and national incidence, prevalence, and mortality of HIV, 1980-2015: the Global Burden of Disease Study 2015. Lancet HIV. 2016;3(8):e361-87.

39. Nachega JB, Adetokunboh O, Uthman OA, Knowlton AW, Altice FL, Schechter M, et al. Community-Based Interventions to Improve and Sustain Antiretroviral Therapy Adherence, Retention in HIV Care and Clinical Outcomes in Low- and Middle-Income Countries for Achieving the UNAIDS 90-90-90 Targets. Current HIV/AIDS Reports. 2016;13(5):241-55.

40. 40. IFRC, GNP+. A community-based service delivery model to expand HIV prevention and treatment 2015 [cited 2016 May 06]. Available from:

http://www.ifrc.org/Global/Documents/Secretariat/ AIDS\%20conference/1281400-HIV-leaflet-LR.pdf.

41. 41. Jacob B, Alana B, Matthew F, Mhairi M, Wendy S, Sergio C, et al. District Prevalence of Unsuppressed HIV in South African Women: Monitoring Program Performance and Progress Towards 90-90-90. AIDS conference, Durban South Africa). The 21st International AIDS Conference to take place on 18-22 July 2016 Durban, South Africa2016. 